DOI: $10.17805 / z p u .2017 .2 .10$

\title{
Язык и культура: опыт культурологической интерпретации художественного замысла в японских и китайских образах
}

\author{
Н. А. ЗАВЬЯЛОВА \\ УРАЛЬСКИЙ ФЕДЕРАЛЬНЫЙ УНИВЕРСИТЕТ \\ ИМ. ПЕРВОГО ПРЕЗИДЕНТА РОССИИ Б. Н. ЕЛЬЦИНА, Г. ЕКАТЕРИНБУРГ; \\ МОСКОВСКИЙ ГУМАНИТАРНЫЙ УНИВЕРСИТЕТ
}

В статье анализируются национальные коммуникативные стили Японии и Китая, раскрывается значимость традиции умолчания для японцев и тенденции заимствований и гиперболизации для китайцев. В центре внимания автора - картина Кацусики Хокусая «Большая волна в Канагаве». Сделана попытка реконструировать замысел художника с учетом широкого исторического контекста: развития соответствующих художественных образов от плейстоцена до современности. Интерпретация идейного содержания картины и карикатур на нее согласовывается с выявленными коммуникативными стратегиями японцев и китайцев.

В статье подвергаются анализу возможные пересечения символов с другой картиной Кацусики Хокусая (1760-1849) “Сожжение изображения Будды». Предлагается авторская интерпретация многочисленных пародий на картину “Большая волна в Канагаве» (1823-1831), созданных китайскими современными художниками Ли Фенем, Ло Дзё (Роджер), Ли Минем. Анализ карикатур позволил автору провести аналогию с инсталляцией популярнейшего китайского дизайнера Ай Вэйвэя «Закон путешествия», выставленной в национальной галерее г. Праги в апреле 2017 г.

Выявленные смыслы выступают в качестве иллюстрации к теории взаимоотражений тезаурусов, сформулированной В. А. Луковым и Вл. А. Луковым. Суть данной теории сводится к положению о том, что ситуацию встречи двух тезаурусов следует рассматривать как ту форму, которую приобретает их диалог, а также последствия этого диалога. Важнейшими основаниями взаимоотражений тезаурусов выступают случаи многочисленных повторов сюжетных линий и мотивов в художественных произведениях. В современности склонность повторять музыкальные участки, фразы известных людей, пословицы и поговорки легла в основу “Эффекта привязки», “Эффекта простой экспозиции», которые чрезвычайно востребованы индустрией рекламы. Проводя аналогию с механизмами копирования участков ДНК, автор приходит к важному выводу о том, что если копирование генов есть механизм онто- и филогенеза, то взаимоотражение культур есть базовый механизм культурогенеза.

Ключевые слова: культурогенез; культура Японии; культура Китая; тезаурусный подход; тезаурус; художественное произведение; коммуникативный стиль; Кацусика Хокусай 


\section{ВВЕАЕНИЕ}

В вязь языка и культуры у каждого народа проявляется по-своему. В рамках данной статьи мы делаем попытку проанализировать эту связь на примере японской и китайской культуры.

В японской культурологической традиции нередко отмечается традиция немногословного общения, намеренного умолчания. Традиция умолчания - важнейшая черта мышления и речевого поведения японцев. Ведущие отечественные японисты поразному интерпретируют эту особенность. Известный российский японист В. П. Мазурик объясняет важность для японцев неспешной, немногословной коммуникации с расплывчатыми границами и невыделенностью субъектно-предикатно-объектных отношений особым «азиатским способом производства». При этом анонимная скоростная манера общения современных европейцев и американцев японцам кажется слишком «жестко-рассудочной (рикуиуппой) и грозящей нарушить традиционное согласие (ba) общины» (Мазурик, 2012: 100). Японский синкретизм обусловливает необходимость умалчания не только в коллективной трудовой деятельности, но и в авторских эстетических проявлениях. Проиллюстрируем данное положение попытками интерпретаций популярной картины Кацусики Хокусая «Большая волна в Канагаве» (Большая волна ... : Электронный ресурс). Анализ интерпретаций данного произведения изобразительного искусства мы будем выстраивать в различных темпоральных направлениях: от олдувайских каменных топоров, чей возраст насчитывает свыше 2,5 млн лет (Stone handaxe ... : Электронный ресурс), до 2016 г. Цель статьи заключается в сопоставительном анализе коммуникативных стратегий японцев и китайцев и культурно-эстетических способах их реализации.

\section{ИСТОРИЯ ОБРАЗА}

Начнем с глубокой древности и издалека. Развивая теорию прекрасного, на основе сформулированной Ч. Аарвином теории эволюции (Darwinian theory of beauty), американский философ-антрополог А. Аатон (D. Dutton) обращает внимание на удивительную правильную форму олдувайских каменных топоров, добиться которой Homo erectus и Homo ergaster стоило огромного труда. Что побудило далеких предков современного человека выдалбливать предметы безупречной каплевидной формы? По мнению А. Аатона, обладание подобными предметами обеспечивало высокий социальный статус и создавало условие для «репродуктивного преимущества» (reproductive advantage) путем привлечения внимания особей противоположного пола. Ученый полагает, что на протяжении всей истории человечества каплевидная форма - воспроизводимый в различных предметах искусства мотив, который актуализирует собой древнейший эстетический опыт, опыт, предшествующий первым человеческим языкам (Dutton, 2010: 15).

Возвращаясь к картине Хокусая, отметим, что большая волна на картине вместе с брызгами представляет собой правильную симметричную каплю - форму, волновавшую человечество с древнейших времен. Аумается, что обращение к каплевидному мотиву обрекло произведение Хокусая на успех у всего человечества, а не только у ценителей японской эстетики. Следуя традиции умолчания, Хокусай не предъявляет нам волну-каплю правильной формы, но разбрызгивает ее край с тем, чтобы зритель сам восстановил утраченную асимметрию.

Среди многочисленных интерпретаций замысла автора данной картины интерес, на наш взгляд, представляет идея, озвученная Е. С. Штейнером в лекции на телекана- 
ле «Культура», согласно которой на картине представлен миф о поворотах колеса Ахармы, великого закона изменчивого мира, получившего свое развитие в японской философской идее укиё (букв. «уплывающий мир») о «быстро текущем мире печали и скорби» (Штейнер: Электронный ресурс). Аобавим к данной интерпретации детали из сферы японского фольклора. Словарь японских фразеологизмов содержит выражения с компонентами «водяная пена», «прилив», «дно». Часть данных выражений маркируют отрицательные фрагменты повседневности. Мидзу-но ава-то нару «стать водяной пеной» - пойти прахом, свестись к нулю. Соко о-цуку - «ткнуть дно» - упасть до предела, исчерпать до конца. Часть выражений, напротив, сигнализируют об удаче и победах. Ий сидоки-о миру — «высмотреть хороший прилив» выбрать удобный момент. Агэсио-ни нору — «сесть верхом на морской прилив» - добиться успеха в жизни, выдвинуться в первые ряды.

Анализ языкового материала свидетельствует о том, что все явления моря, равно как и явления жизни, веселые и грустные, составляют единое целое. Сегодня накрывающая тебя с головой водяная пена завтра может стать хорошим приливом. Возможно, Хокусай посредством своей картины сообщает нам некий заряд осторожного оптимизма, указывая на то, что и грозные волны не вечны. Рыбакам необходимо двигаться вперед, невзирая на кажущуюся опасность.

В искусствоведении существуют иные политико-экономические интерпретации данного произведения. Время его создания приходится на первую половину XIX в. Эта эпоха в истории Японии известна своим пересмотром взглядов на политику «закрытой страны», когда в Японию все-таки начали активно поступать товары из Португалии и Голландии. В целом вся картина выполнена в традиционной для японского искусства приглушенной серо-бело-розовой гамме, но сама волна, насыщенная по цвету, ярко синяя, изображена при помощи нетрадиционного для японских живописцев оттенка «берлинская глазурь». Что известно об этом оттенке? В Японии эту краску во времена создания картины не производили, к Хокусаю, она, возможно, попала вместе с европейскими товарами либо из Китая (Keene, 1981: 123). Будучи иностранной по своей кричащей цветовой гамме, волна, возможно, олицетворяла собой насильственный накат на Японию со стороны европейцев. Гребни волн - словно расставленные широко пальцы злодеев - угрожают маленькой Фудзи с моря. Образ варварского злодея с широко расставленными пальцами, глумящегося над сакральными святынями, на наш взгляд, воспроизведен Хокусаем на картине «Сожжение изображения Будаы». Огонь в центре картины словно кровь сердца японца, сгорающего вместе с Буддой (Burning a Buddhist Image ... : Электронный ресурс).

Развивая идею злодейского проникновения, сюжетом картины «Волна» Хокусай, возможно, хотел сказать современникам о том, что утлые суденышки местных рыбаков - жалкая игрушка для варваров из Европы и США, которые вскоре насильственно вскроют таинственную драгоценную раковину Страны восходящего солнца, страны, которую сами японцы отделяли от остального мира, описывая ее как государство особого типа: сима гуни - «островная страна». Возвращаясь к возможной аналогии волны - капли - древнего топора, отметим, что художнику удалось подчеркнуть искусственно-насильственный характер взаимодействия европейско-американского мира, прибегнувшего к специальным орудиям для установления диалога с японцами.

Процедура насильственного вскрытия будет повторена не единожды в истории, что провидчески представил в своей работе Хокусай. 
Коммуникативная традиция умолчания, реализованная Хокусаем в образе волны, накрывающей главную героиню картинного цикла «36 видов Фудзи» (1830) - священную для японцев гору Фудзияму, позволила художнику высказать зрителю целый набор мировоззренческих идей, которые мы продолжаем интерпретировать и по сей день.

\section{ИНТЕРПРЕТАЦИИ СОВРЕМЕННИКОВ}

Современность постоянно обращается к шедевру Хокусая, обнаруживая новые грани преломления смыслов исходного сюжета. Здесь мы переходим на китайскую почву, которая по коммуникативным стратегиям, на наш взгляд, представляет собой полную кричашую противоположность молчаливых японцев. На карикатуре «Аилемма» китайского художника $\Lambda$ Фена (р. 1988), размещенной на новостном портале «Чайна Аэйли» (China Daily), устрашающие гребни волн заменены ракетами с боеголовками, целящимися не в жалкое суденышко местных рыбаков, а в кораблик с иммигрантами, направляющимися из Ближнего Востока в Европу ( ААлемма», 2016) (Ии Фен ... : Электронный ресурс). Со времен Хокусая угрозы ударов колеса Ахармы превратились из гребней морской пены в оружие массового поражения. Отметим, что если в оригинале Хокусай все-таки сохраняет для рыбаков шанс преодолеть разрушительную силу волны путем смиренного проникновения в ее основание, то на карикатуре китайского художника у странников нет никакой надежды справиться с боеголовками ИГИ $\Lambda$ (Исламского государства Ирака и Аеванта - террористической организации), они в панике бегут в обратном направлении и трагически наталкиваются на каменные волны-стены Евросоюза. В XXI в., по мнению китайского художника, человечество начисто лишено шансов на выживание в мире оружия и бюрократии.

Анализируя данную карикатуру с позиции художественной ценности, можно говорить о том, что нам явлена китайская манера кричащего заимствования, характерная для всего культурологического уклада современного Китая.

Аалее рассмотрим еще один вариант карикатуры на портале «Чайна Аэйли» (China Daily), на наш взгляд, иллюстрирующий очередной поворот колеса Ахармы, но на утлом суденышке на этот раз расположилась напуганная волной иммигрантов канцлер Германии А. Меркель. Автор карикатуры - Ао Азё (Роджер) (р. 1981) сохраняет название «Волна» для своей версии (Ио Азё ... : Электронный ресурс). Волна нелегальных иммигрантов выглядит безбрежной, в ее основании и гребне - судьбы обычных людей, попавших в водоворот жизни вынужденных беженцев. Сравнивания эту карикатуру с предыдущей, можно с уверенностью сказать о том, что движение колеса Ахармы постоянно меняет положение героев относительно оси «верх - низ». Если сегодня некто располагается у основания волны, в самом низу, с ужасом наблюдая приближение стихии, то завтра эта же стихия может вытолкнуть несчастного на самый верх, позволяя тем самым развитие самых фантастических сценариев.

Прорисовка отдельных лиц героев, данных в огромной массе, - следующая культурологическая черта китайского способа коммуникации. Нередко китайское национальное мышление сравнивается с гиперболой, в основе которой лежит намеренное преувеличение массовости явления. В этой традиции, на наш взгляд, выполнена новая инсталляция известного современного китайского художника Ай Вэйвэя «Закон путешествия» (2017), созданная на площадке в национальной галерее Праги (Китайский художник заставляет ..., 2017: Электронный ресурс). 
Основы намеренно преувеличенной масштабности явления находим в захоронениях императора Цинь Шихуанди, сопровождаемого своей знаменитой на весь мир терракотовой армией (Иллюстрированный журнал ... : Электронный ресурс).

Возвращаясь к карикатурам по мотивам «Волны» Хокусая, отметим следующий сюжет мифа о колесе Ахармы, посвященный японо-американскому противостоянию на острове Окинава, где 60 тыс. жителей выступили с протестами и требованием закрыть американскую военную базу на их территории летом 2016 г. Китайский художник $\Lambda$ Минь (р. 1985) на карикатуре, размещенной на портале «Чайна Аэйли» (China Daily), изображает протестующих в виде волны, угрожающей Аяде Сэму («Волна», 2016) (Ии Минь ... : Электронный ресурс). Но какой ощутимый ущерб может причинить волна современной военной технике США? Ответ китайского художника очевиден. Хотя Аядя Сэм и напуган гневом жителей острова Окинава, его мощный военный самолет не собирается лететь домой в США, он располагается на прочном фундаменте укрепленной военной базы. Самолет направлен строго в основание волны с тем, чтобы пережить и эту стихию, как бывало не раз. Колесо Ахармы провернется снова, и все будет, как прежде.

\section{МЕХАНИЗМ НАМЕРЕННОГО ПОВТОРА}

Рассмотренные примеры свидетельствуют о существующем японо-китайском культурном диалоге. Однако каждая сторона выстраивает его по законам своих коммуникативных стратегий: японцы, следуя традиции умолчания, а шумные китайцы громко предъявляют свои взгляды миру, нередко намеренно гиперболизируя их содержание. Проанализированный прием заимствования мотива картины Хокусая представляет собой намеренную игру с аудиторией. Каковы базовые механизмы, лежащие в ее основе?

Суть анализируемого явления сводится к одному - механизму намеренного повтора. Значимость данного механизма для онто- и филогенеза огромна. Сам феномен повтора находится в центре внимания целого ряда современных наук. В психологии описаны эффект привязки (от англ. anchoring, adjustment) (Fombrun, Shanley, 1990), эффект чистой экспозиции (от англ. теre ехроsиre effect), когда знакомая, повторяемая несколько раз информация, припев, отрывки текстов воспринимаются как более точные, вызывают симпатию и доверие (Zajonc, 2001). Аанные эффекты легли в основу рекламных роликов, маркетинговых стратегий (Fang, Singh, Ahluwalia, 2007). Экспериментальные данные свидетельствуют о том, что человек восприимчив к повторам даже в перинатальный период (Jacoby, Dallas, 1981).

В отечественном литературоведении сложная природа повтора зафиксирована и описана в тезаурусной концепции мировой культуры, разработанной В. А. Ауковым и Вл. А. Ауковым. В рамках данной концепции авторы указывают на повторяемые явления в различных культурных тезаурусах, оперируя при этом несколькими важными явлениями: «парадоксом Элиота», теорией взаимоотражений и особой «рещептивной эстетикой» (Иуков, 2012). Сущность первого явления сводится к тому, что крупнейший англосаксонский поэт и теоретик культуры XXв. Т. С. Элиот подразумевал под понятием «традиция ». По его мнению, все, что рождается в творчестве, не отражает авторской позиции, а вписано в исторический культурный контекст определенной традиции, актуализированной в сознании автора «чувством истории» (Элиот, 1987). Теория взаимоотражения описывает «ситуацию встречи двух тезаурусов, ту форму, которую приобретает их диалог, последствия этого диалога» (Иуков, 2012: 30). 
Отметим, что механизм взаимоотражения глубоко укоренен в эволюционном процессе. Американский философ Р. Аокинз в своем научно-популярном труде «Рассказ предка. Паломничество к истокам жизни» следующим образом описывает суть механизма передачи генов: «...в отношении эволюции мы располагаем... воспроизводимой информацией, которая претерпела невообразимо большое число случаев копирования и которую, позволив себе небольшую поэтическую вольность, мы можем расценивать как аналог письменного текста. Эти исторические записи с поразительной точностью воспроизводились сотни миллионов раз благодаря тому, что в их основе, как и в основе письменности, лежит самоупорядочивающийся алфавит. Информация АНК передается с потрясающей точностью. Отдельные атомы в ней непрерывно меняются, однако информация, которую они кодируют, копируется в течение миллионов, даже сотен миллионов лет» (Аокинз, 2015, 35). Можно сделать вывод о том, что механизм повтора (копирования) прочно встроен в основу филогенеза. Копии, подвергшиеся авторской художественной переработке, - взаимоотражение, рецептивная әстетика - суть культурогенеза (Завьялова, 2016).

Однако у повтора, безусловно, есть и обратная сторона. Если Р. Аокинз расценивает повтор как явление положительное, способствующее эволюционному прогрессу, то в работе нобелевского лауреата по экономике А. Канемана именно легко повторяемые иногда ошибочные суждения, создающие эффект мнимой «когнитивной легкости», мнимой «когерентной съязности», критикуются автором за «подсказывание» неправильного, но простого, легко узнаваемого эмоционального интуитивного ответа, данного на основе прошлого опыта, выдвигаемого без должной оценки в настоящем. Подобный ответ нередко является ошибочным, ведущим человека по ложному следу в тупик. «В море жизни мы отдаемся на волю впечатлений и чувств. Нередко наша уверенность в интуитивных догадках и предпочтениях оправданна, но так случается не всегда. Ааже когда мы не правы, мы уверены в обратном. И лишь объективное наблюдение со стороны позволяет найти ошибку, которую мы пропустили» (Kahneman, 2011: 4; перевод наш. - H. 3.). Выбор в пользу простого стереотипного ответа - это выбор в пользу повтора, основанного на явлениях прошлого, на явлениях ретроспекиии.

Важность ретроспекции для повседневной жизни подчеркивает в своих исследованиях российский культуролог В. А. Аелеко: «Настоящее есть постоянно пребывающее прошлое. <..> Аля повседневности характерно наличие дальней временной перспективы, особенно в направлении настоящее - прошлое. Повседневность ретроспективна. <...> Настоящее мыслится как проекция прошлого» (Иелеко, 2002: 80-85). Американский социолог Аж. Александер обращает внимание на то, что история постоянно нуждается в символических репрезентациях и символах, понятных каждому: «История не ждет. Она требует производства репрезентаций, и они будут произведены... Ааже в целом незнакомое будет сделано знакомым» (Alexander, 2003: 33; перевод наш. - H. 3.). Обратим внимание на важнейший вывод, к которому приходит автор: «То, что произошло раньше, наиболее важно для культурного процесса кодирования, оценивания и повествования» (там же).

\section{ЗАКАЮЧЕНИЕ}

Рассмотренные идеи и примеры позволяют нам подтвердить вывод о том, что между языком и культурой есть многочисленные связи, проявляющиеся в манерах коммуникации слов и художественных идей. Если для японцев характерна әстетика не- 
досказанности, речевая традиция умалчивания, то китайцы выражают свои мнения в крикливой манере, прибегая при этом к многочисленным заимствованиям и гиперболам. Аругим значимым выводом является важность механизма повтора, взаимоотражения, рецепции и ретроспекции для мирового культурогенеза. Этот механизм заслуживает пристального внимания специалистов из разных сфер науки, поскольку его кумулятивное изучение обеспечивает масштабные достоверные результаты.

\section{СПИСОК АИТЕРАТУРЫ}

Большая волна в Канагаве [Электронный ресурс]// Wikimedia. URL: https://commons.wikimedia.org/w/index.php?curid=2646210 (дата обращения: 05.04.2017).

Аокинз, Р. (2015) Рассказ предка. Паломничество к истокам жизни / пер. с англ. С. Аолотовской. М. : Издательство ACT : CORPUS. 768 с.

Завьялова, Н. А. (2016) Повторяющиеся культурные микротексты: диахронный и синхронный аспекты // Знание. Понимание. Умение. № 2. С. 124-137. DOI: 10.17805/zpu.2016.2.11

Иллюстрированный журнал Владимира Аергачёва «Иандшафты жизни» [Электронный ресурс]// LIVEJOURNAL. URL: http://dergachev-va.livejournal.com/52117.html (дата обращения: 05.04.2017).

Китайский художник заставляет посмотреть на проблему с беженцами своей новой инсталляцией (ФОТО) (2017) [Электронный ресурс] // GOGETNEWS.INFO. 2 апреля. URL: http:// www.gogetnews.info/no-comments/153465-kitayskiy-hudozhnik-zastavlyaet-posmotret-na-problemu-s-bezhencami-svoey-novoy-installyaciey-foto.html (дата обращения: 05.04.2017).

Корчагина, Т. И., Нечаева, А. Т. (2012) О конференции «Методика преподавания японского языка» // Япония наших дней. № 4 (14). С. 132-139.

Иелеко, В. А. (2002) Пространство повседневности в европейской культуре. СПб. : С.-Петерб. гос. ун-т культуры и искусств. 302 с.

$\Lambda$ и, Минь (2016) Волна [Электронный ресурс] // cn.chinadaily.com. URL: http://cn.chinadaily.com.cn/2016-06/21/content_25784336.htm (дата обращения: 05.04.2017). (На кит. яз.).

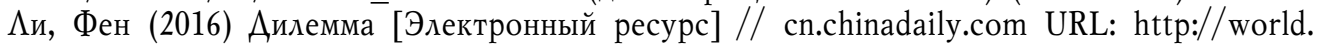
chinadaily.com.cn/2015-09/01/content_21764737.htm 156596 (дата обращения: 08.03.2017). (На кит. яз.).

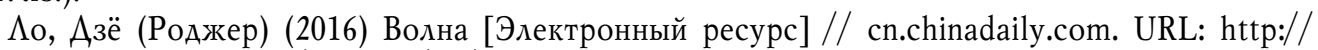
world.chinadaily.com.cn/2016-01/18/content_23144038.htm (дата обращения: 08.03.2017) (На кит. яз.).

Ауков, Вл. А. (2012) Тезаурусный «парадокс Элиота» и понятие «взаимоотражение» в художественной культуре // Знание. Понимание. Умение. № 1. С. 26-33.

Мазурик, В. П. (2012) Фигуры умолчания в японской классической поэтике // Материалы научно-методической конференции «Японский язык в вузе» (октябрь, 2012 г.) / под общ. ред. $\Lambda$. Т. Нечаевой. М. : Ключ-С. 159 с. С. 100-111.

Штейнер, Е. С. (2010) Японское искусство: мир зыбкой гармонии (часть 1) [Электронный ресурс] // TVKULTURA.ru. Проект «Academia». URL: http://tvkultura.ru/video/show/brand_id/ 20898/episode_id/156596 (дата обращения: 08.03.2017).

Элиот, Т. С. (1987) Традиция и индивидуальный талант // Зарубежная эстетика и теория литературы XIX-XX вв.: Трактаты, статьи, эссе / сост., общ. ред. и вступит. ст. Г. К. Косикова. М. : ИзА-во Московского университета. 510 с. С. 123-145.

Alexander, C. J. (2003) The Meanings of Social Life: A Cultural Sociology. Oxford University Press. 296 p.

Burning a Buddhist Image [Электронный pecypc] // Freer Sackler. URL: http:// www.asia.si.edu/collections/edan/object.php?q=fsg_F1904.210\&bcrumb=true (дата обращения: 05.04.2017).

Dutton, D. (2010) The Art Instinct: Beauty, Pleasure, and Human Evolution. Oxford : Oxford University Press. ISBN 1-60819-055-2. 
Jacoby, L. L., Dallas, M. (1981) On the relationship between autobiographical memory and perceptual learning // Journal of Experimental Psychology. № 110 (3). P. 306-340. DOI: 10.1037/00963445.110.3.306

Kahneman, D. (2011) Thinking, Fast and Slow. New York : Farrar, Straus and Giroux. 512 pp.

Fang, X., Singh, S., Ahluwalia, R. (2007) An Examination of Different Explanations for the Mere Exposure Effect // Journal of Consumer Research. № 34. P. 97-103.

Fombrun, Ch., Shanley, M. (1990) What's in a Name? Reputation Building and Corporate Strategy // The Academy of Management Journal. № 33 (2). P. 220-256.

Keene, D. (1981) Appreciations of Japanese Culture. Kodansha Amer. Inc. 343 p.

Stone handaxe [Электронный ресурс] // Google Arts \& Culture. URL: https://www. google. com/culturalinstitute/beta/asset/stone-handaxe/vAEJaM2CK6iu1A (дата обращения: 05.04.2017).

Zajonc, R. B. (2001) Mere Exposure: A Gateway to the Subliminal // Current Directions in Psychological Science. № 10 (6). DOI: 10.1111/1467-8721.00154.

Аата поступления: 15.02.2017 2.

\section{LANGUAGE AND CULTURE: THE EXPERIENCE OF CULTURAL INTERPRETATION OF ARTISTIC DESIGN IN JAPANESE AND CHINESE IMAGES \\ N. A. ZAVYALOVA \\ URAL FEDERAL UNIVERSITY NAMED AFTER THE FIRST PRESIDENT OF RUSSIA \\ B. N. YELTSIN; MOSCOW UNIVERSITY FOR THE HUMANITIES}

The article analyses Japanese and Chinese national communicative styles. The author stresses the significance of the reticence tradition for the Japanese and the tendency of borrowing and hyperbolization for the Chinese. The research focuses on Katsushika Hokusai's famous painting "The Great Wave in Kanagawa". The author makes an attempt to reconstruct the artist's intention, resorting to a wide historical context: from the Pleistocene to the modern era. The interpretation of the ideological content of the painting and its caricatures is coordinated with the revealed communicative strategies of the Japanese and Chinese people.

The paper carefully examines possible intersections of symbols with another painting by Katsushika Hokusai (1760-1849) "Burning the Buddha Image". It also gives the author's interpretation of numerous parodies of the painting "The Great Wave in Kanagawa"(1823-1831), created by the contemporary Chinese artists Li Feng, Luo Jyo (Roger), Li Ming. The analysis of the caricatures allowed the author to draw an analogy with the installation of a very popular Chinese designer $\mathrm{Ai}$ Weiwei "Travel Law", exhibited in the National Gallery of Prague in April 2017.

The revealed meanings serve as an illustration to the theory of thesauri interreflections, formulated by V. A. Lukov and Vl. A. Lukov. The essence of this theory results in the proposition that the situation of the meeting of two thesauri should be considered as the form that their dialogue acquires, as well as the consequences of this dialogue. The most important foundations for the reflection of thesauri are the cases of numerous repetitions of plot lines and motives in works of art. In modern times, the tendency to repeat musical parts, phrases of famous people, proverbs and sayings formed the basis of the "anchor effect", or the "mere exposure effect". These effects are extremely popular strategies in modern advertising industry. Drawing an analogy with the copying mechanisms of DNA sections, the author comes to the important conclusion that if copying genes is a mechanism of onto- and phylogenesis, then the interreflection of cultures is the basic mechanism of cultural genesis.

Keywords: cultural genesis; Japanese culture; Chinese culture; thesaurus approach; thesaurus; work of art; communicative style; Katsushika Hokusai

Bol'shaia volna v Kanagave. Wikimedia [online] Available at: https://commons.wikimedia.org/ w/index.php?curid=2646210 (access date: 05.04.2017). (In Russ.). 
Dokinz, R. (2015) Rasskaz predka. Palomnichestvo k istokam zhizni, transl. by Engl. by S. Dolotovskaya. Moscow, AST; CORPUS. 768 p. (In Russ.).

Zav'ialova, N. A. (2016) Povtoriaiushchiesia kul'turnye mikroteksty: diakhronnyi i sinkhronnyi aspekty. Znanie. Ponimanie. Umenie, no. 2, pp. 124-137. DOI: 10.17805/zpu.2016.2.11 (In Russ.).

Illiustrirovannyi zhurnal Vladimira Dergacheva "Landshafty zhizni". LIVEJOURNAL [online] Available at: http://dergachev-va.livejournal.com/52117.html (access date: 05.04.2017). (In Russ.).

Kitaiskii khudozhnik zastavliaet posmotret' na problemu s bezhentsami svoei novoi installiatsiei (FOTO) (2017). GOGETNEWS.INFO, 2 April [online] Available at: http://www.gogetnews.info/nocomments/153465-kitayskiy-hudozhnik-zastavlyaet-posmotret-na-problemu-s-bezhencami-svoeynovoy-installyaciey-foto.html (access date: 05.04.2017). (In Russ.).

Korchagina, T. I. and Nechaeva, L. T. (2012) O konferentsii "Metodika prepodavaniia iaponskogo iazyka". Iaponiia nasbikb dnei, no. 4 (14), pp. 132-139. (In Russ.).

Leleko, V. D. (2002) Prostranstvo povsednevnosti v evropeiskoi kul'ture. St. Petersburg, S.-Peterb. gos. un-t kul'tury i iskusstv. 302 p. (In Russ.).

Li, Min' (2016) Volna.cn.chinadaily.com [online] Available at: http://cn.chinadaily.com.cn/201606/21/content_25784336.htm (access date: 05.04.2017). (In Chinese).

Li, Fen (2016) Dilemma. cn.chinadaily.com [online] Available at: http://world.chinadaily.com.cn/ 2015-09/01/content_21764737.htm 156596 (access date: 08.03.2017). (In Chinese).

Lo, Dze (Rodzher) (2016) Volna. cn.chinadaily.com [online] Available at: http://world.chinadaily.com.cn/2016-01/18/content_23144038.htm (access date: 08.03.2017) (In Chinese).

Lukov, Vl. A. (2012) Tezaurusnyi "paradoks Eliota" i poniatie "vzaimootrazhenie" v khudozhestvennoi kul'ture. Znanie. Ponimanie. Umenie, no. 1, pp. 26-33. (In Russ.).

Mazurik, V. P. (2012) Figury umolchaniia v iaponskoi klassicheskoi poetike. In: Materialy nauchno-metodicheskoi konferentsii "Iaponskii iazyk v vuze" (oktiabr', 2012 g.), ed. L. T. Nechaeva. Moscow, Kliuch-S. 159 p. Pp. 100-111. (In Russ.).

Shteiner, E. S. (2010) Iaponskoe iskusstvo: mir zybkoi garmonii (chast' 1). TVKULTURA.ru. Proekt "Academia" [online] Available at: http://tvkultura.ru/video/show/brand_id/20898/episode_id/156596 (access date: 08.03.2017). (In Russ.).

Eliot, T. S. (1987) Traditsiia i individual'nyi talent. In: Zarubezhnaia estetika i teoriia literatury XIX-XX vv.: Traktaty, stat' $i$, esse, comp., ed. G. K. Kosikov. Moscow, Moskovskii universitet Publ. 510 p. Pp. 123-145. (In Russ.).

Alexander, C. J. (2003) The Meanings of Social Life: A Cultural Sociology. Oxford University Press. 296 p.

Burning a Buddhist Image. Freer Sackler [online] Available at: http://www.asia.si.edu/collections/edan/object.php?q=fsg_F1904.210\&bcrumb=true (access date: 05.04.2017).

Dutton, D. (2010) The Art Instinct: Beauty, Pleasure, and Human Evolution. Oxford : Oxford University Press. ISBN 1-60819-055-2.

Jacoby, L. L. and Dallas, M. (1981) On the relationship between autobiographical memory and perceptual learning. Journal of Experimental Psychology, no. 110 (3), pp. 306-340. DOI: 10.1037/0096-3445.110.3.306

Kahneman, D. (2011) Thinking, Fast and Slow. New York, Farrar, Straus and Giroux. 512 p.

Fang, X., Singh, S. and Ahluwalia, R. (2007) An Examination of Different Explanations for the Mere Exposure Effect. Journal of Consumer Research, no. 34, pp. 97-103.

Fombrun, Ch. and Shanley, M. (1990) What's in a Name? Reputation Building and Corporate Strategy. The Academy of Management Journal, no. 33 (2), pp. 220-256.

Keene, D. (1981) Appreciations of Japanese Culture. Kodansha Amer. Inc. 343 p.

Stone handaxe. Google Arts \& Culture [online] Available at: https://www.google.com/culturalinstitute/beta/asset/stone-handaxe/vAEJaM2CK6iu1A (access date: 05.04.2017). 
Zajonc, R. B. (2001) Mere Exposure: A Gateway to the Subliminal. Current Directions in Psychological Science, no. 10 (6). DOI: 10.1111/1467-8721.00154.

Submission date: 15.02.2017.

Завьялова Наталья Алексеевна - кандидат филологических наук, доцент, доцент Уральского федерального университета им. первого Президента России Б. Н. Ельцина, докторант кафедры социологии Московского гуманитарного университета. Адрес: 620002, Россия, г. Екатеринбург, ул. Мира, д. 19. Тел.: +7 (343) 375-44-44. Эл. алрес: N.A.Zavialova@urfu.ru

Zavyalova Natalya Alekseevna, Candidate of Philology, Associate Professor, Ural Federal University named after the first President of Russia B. N. Yeltsin; Doctoral Researcher, Department of Sociology, Moscow University for the Humanities. Postal address: 19, Mira St., Yekaterinburg, Russian Federation 620002. Tel.: +7 (343) 375-44-44. E-mail: N.A.Zavialova@urfu.ru 